\title{
Therapeutic interventions in intimate partner violence: an overview
}

\author{
Valeria Condino, ${ }^{1}$ Annalisa Tanzilli, ${ }^{2}$ Anna Maria Speranza, ${ }^{2}$ Vittorio Lingiardi ${ }^{2}$ \\ ${ }^{1}$ Humanistic Studies Department, Carlo Bo University of Urbino, Urbino; ${ }^{2}$ Department of Dynamic and Clinical Psychology, \\ Sapienza University of Rome, Rome, Italy
}

\begin{abstract}
Intimate partner violence (IPV) is associated with significant morbidity and mortality, and its prevention is a global public health priority. There is strong scientific evidence that suggests IPV and symptoms such as anxiety, depression, post-traumatic stress disorder, substance abuse, chronic pain, etc. are linked. Despite recommendations and various interventions for the treatment of IPV that have been tried in these last 20 years, the rates of recurrence are still too high. Furthermore, there is a lack of research evidence for the effectiveness of the most common treatments provided for victims and perpetrators of IPVs. The purpose of this paper is to present most used, at a global level, therapeutic interventions for women experiencing IPV (as well as treatments for perpetrators). The possibility of building a preliminary theoretical and clinical model is discussed.
\end{abstract}

Key words: Intimate partner violence; Therapeutic interventions; Treatment; Well-being.

\section{Introduction}

In the last 20 years many epidemiological studies have investigated the prevalence of violence against women. The report developed by the World Health Or-

Correspondence: Valeria Condino, Humanistic Studies Department, Carlo Bo University of Urbino, via Bramante 17, 61029 Urbino (PU), Italy.

Tel: +39.320.6166487.

E-mail: v.condino@campus.uniurb.it

Citation: Condino, V., Tanzilli, A., Speranza, A.M., \& Lingiardi, V. (2016). Therapeutic interventions in intimate partner violence: an overview. Research in Psychotherapy: Psychopathology, Process and Outcome, 19(2), 79-88. doi: 10.4081/ripppo.2016.241

Acknowledgments: the authors would like to thank Molfino family for their encouragement and support in the preparation of this work.

Conflict of interest: the authors declare no potential conflict of interest.

Funding: this paper was made possible through a grant from the Foundation for the promotion of study and research in memory of Francesca Molfino.

Received for publication: 12 September 2016.

Revision received: 9 October 2016.

Accepted for publication: 10 October 2016.

This work is licensed under a Creative Commons Attribution NonCommercial 4.0 License (CC BY-NC 4.0).

C Copyright V. Condino et al., 2016

Licensee PAGEPress, Italy

Research in Psychotherapy:

Psychopathology, Process and Outcome 2016; 19:79-88

doi:10.4081/ripppo.2016.241 ganization (WHO), the London School of Hygiene and Tropical Medicine and the South African Medical Research Council (World Health Organization, 2013), presents the first global systematic review of 141 studies in 81 countries.

Recent global prevalence figures indicate that about 1 in $3(35 \%)$ of women worldwide have experienced either physical and/or sexual intimate partner violence (IPV) or non-partner sexual violence in their lifetime. Most of this violence is IPV. Worldwide, almost one third (30\%) of women who have been in a relationship report that they have experienced some form of physical and/or sexual violence by their intimate partner. The report also details that globally as many as $38 \%$ of murders of women are committed by an intimate partner (World Health Organization, 2013).

Violence against women is a significant public health problem, as well as a fundamental violation of women's human rights (World Health Organization, 2013), but it is not a new phenomenon, nor are its consequences on women's physical, mental and reproductive health. What is new is the growing recognition that acts of violence against women are not isolated events but they rather form a pattern of behavior that violates the rights of women and girls, limits their participation in society, and damages their health and well being.

The term violence against women indicates many forms of violence, including violence by an intimate partner and rape/sexual assault and other forms of sexual violence perpetrated by someone other than a partner (non-partner sexual violence), as well as female genital mutilation, trafficking of women, etc. In the present paper we will focus on physical and/or sexual IPV and on the available research regarding evidencebased treatments. 


\section{Risk factors for intimate partner violence victimization and its consequences}

IPV is associated with significant morbidity and mortality, especially among women, and its prevention is a global public health priority (Khalifeh, Oram, Trevillion, Johnson, \& Howard, 2015). IPV includes a range of abusive behaviors perpetrated by someone who is or was involved in an intimate relationship with the victim. Although IPV affects both men and women as victims and perpetrators, more women experience IPV and most studies about screening and interventions for IPV enrol women (Nelson, Bougatsos, \& Blazina, 2012). The prevalence of IPV can vary depending upon several risk factors, including previous victimizations, homelessness, poverty, and the presence of children in the household (Bair-Merritt, Holmes, Holmes, Feinstein, \& Feudtner, 2008; Breiding, Black, \& Ryan 2008; Thompson et al., 2006).

Areas of psychopathology that have received attention as risk factors for IPV include both the externalizing and internalizing domains. Conduct problem or antisocial behavior has emerged as a substantial risk factor for later IPV involvement for men and women who perpetrate IPV and are frequently found to be a mediator for earlier risk factors such as harsh parental treatment (Capaldi, Knoble, Shortt, \& Kim, 2012). In contrast, in the internalizing domain, fewer studies were identified; findings for depressive symptoms indicate that they are associated with IPV perpetration and victimization, but that this association is not robust in multivariate analyses. To be a victim of IPV increases the odds of incidence of depressive symptoms and of suicide attempts among women (Devries et al., 2013). However, the authors of this review are not able to draw firm conclusions because of the quality of the available studies, in particular the lack of adjustment for common risk factors.

Female survivors of IPV report more physical and mental health problems than women who do not report partner abuse, including increased use of general health services (Miller, Cohen, \& Rossman, 1993) and greater likelihood of injuries and death from physical and sexual assault; sexually transmitted infections, including human immunodeficiency virus; pelvic inflammatory disease; unintended pregnancy; and psychological distress. Assaults during pregnancy adversely affect the health of pregnant women and newborns, and IPV is associated with preterm birth, low birth-weight, and decreased gestational age. Long-term conditions that are associated with IPV include chronic pain, neurologic disorders, gastrointestinal disorders, migraine headaches, and other physical disabilities, as well as posttraumatic stress disorder, depression, anxiety disorders, substance abuse, and suicide (Black et al., 2011; Campbell, Sullivan, \& Davidson, 1995; Golding, 1999; Kessler et al., 1994). Testimonies of many women show the progressive physical and emotional isolation they are forced by their partners. In these couples, the behavior of men complaint as well as a severely impaired reflective function. All forms of abuse - psychological, economic, emotional and physical - come from the abuser's desire for power and control (Fonagy, 1999).

Not only is the prevalence of IPV alarmingly high, but also its chronicity is of equal concern. In a large survey, Thompson and colleagues (2006) found that $21 \%$ of women who had experienced IPV were victimized by multiple partners and between 5 and 13\% experienced IPV for more than 20 years. Empirical evidence suggests that survivors of child maltreatment are 2 to 3 times more likely to experience interpersonal forms of adult victimization than individuals who fail to report childhood victimization (Classen, Palesh, \& Aggarwal, 2005). In a nationally representative sample of 16,000 male and female participants, Desai and colleagues (2002) found strong associations between childhood physical and sexual abuse, and risk for violence by a current intimate partner. Specifically, women who experienced childhood sexual abuse were 6 times more likely to experience sexual abuse by a current intimate partner and 3 times more likely to experience violence in their current relationships. Although much of the empirical evidence for re-victimization emphasizes sexual re-victimization, researchers have documented an association between a history of adverse childhood experiences (e.g., abuse, witnessing violence) and an increased risk for experiencing physical and emotional re-victimization in early adulthood (e.g., Bensley, Van Eenwyk, \& Wynkoop Simmons, 2003).

The effect of IPV victimization on mental health consequences in women has been documented in numerous longitudinal studies (e.g. Lawrence, Orengo, Langer, \& Brock, 2012), suggesting that IPV experiences may be important antecedents of adverse health outcomes (Ehrensaft, Moffitt, \& Caspi, 2006). Despite the prevalence and the deleterious effects of IPV on women, there has been comparatively little attention given to IPV in the psychotherapy literature to aid therapists who treat women in abusive relationships (Bogat, Garcia, \& Levendosky 2013); there have been few randomized control trial (RCT) interventions testing the efficacy of therapeutic intervention as a way of reducing women's exposure to IPV (Miller, Howell, \& Graham-Bermann, 2014). The authors (Bogat et al., 2013) claim there are three main reasons as to why so little literature has focused on psychotherapy with women in abusive relationships. The first proposed reason is that the focus of most interventions has been to protect women from violence (e.g., helping women to obtain restraining orders, offering housing in a domestic violence shelter). The second one is the difficulty in creating a professional dialogue among women in abusive relationships that is anything other than survivor oriented (Stein, 2012). The third one is the widely held myth that IPV always involves severe physical violence and that it is only male perpetrated. To this we might add that because IPV is not a diagnosis, it is very difficult to find studies that investigate this clinical 
population - by definition a RCT must have a well-defined population also recognized by the DSM - while the phenomenon of IPV is made up of a series of disorders from the internalizing/externalizing range. Nevertheless, it is important to note that the DSM-5 included in its II Section, within Other conditions that may be a focus of clinical attention (American Psychiatric Association, 2013), the relational problems that may characterize intimate adult partner relationships. It is recognized that these conditions (such as physical or sexual violence, neglect, or psychological abuse of the spouse or partner) have a considerable impact on the health of the individuals, and in the most extreme cases of maltreatments or violence the medical and psychological consequences were considered a focus of the clinician's attention either as the reason that the individual seeks health care or as a problem that unavoidably affects the course, prognosis, or clinical treatment of mental or other medical disorders.

Despite the lack of literature, several researchers and clinicians have started studies to understand, assess and treat IPV cases. They have identified a number of etiologic models to explain the phenomenon, and to highlight the risk factors that can predict their occurrence and to support the development of future IPV treatments (Eckhardt, Murphy, \& Sprunger, 2014). Starting from these studies, the aim of this paper is to provide the presentation of therapeutic interventions for women experiencing IPV (as well as perpetrator treatments), most used worldwide in the treatment of IPV. We conclude with a discussion about the possibility of outlining specific and non-specific elements for a psychotherapeutic intervention for the treatment of women victims of violence, also for preventing recurrence.

\section{Interventions for intimate partner violence}

Given the alarmingly high prevalence of IPV (World Health Organization, 2013) and the serious physical, psychological, and interpersonal impact experienced by victims of such abuse (e.g., Dutton, 2006; Golding, 1999) and by children witnessing a parent being assaulted (Carter, Weithorn, \& Behrman, 1999), counteracting and reducing this phenomena with epidemic proportions represents a crucial challenge for the World Health Organization (WHO) and all the ministries of health, non-governmental organizations, and national agencies worldwide.

In Europe and the United States psychologists have contributed to the research, clinical evaluation, intervention and prevention of domestic violence. Each country has unique factors that determine the services and resources available to abused women, to children exposed to domestic violence and to abused partners. However, what ultimately determines the vulnerability and the safety of women are factors such as gender interaction, political structure, religious claims, attitudes towards violence in general and violence against women, as well as state sponsored violence, for example civil conflicts and wars, and migrations from and between countries.

Support services for women who have suffered violence and for men who have exercised violence in intimate relationships have increased in Spain and specifically in the autonomous region of Cataluña. The Contexto Programme, for example, is a community-based intervention program for intimate partner violence offenders, implemented at the University of Valencia, Spain. It is based on the ecological model framework (Heise, 1998), recommended by the WHO (Dahlberg \& Krug, 2002; Merlo, 2011). The main objective of the program is to reduce risk factors and increase protective factors for violent behavior against women in intimate relationships, taking into account four levels of analysis: individual, interpersonal, situational and macro-social (Lila et al., 2010). Some projects (among which those led by the Asociación de Asistencia a Víctimas de Agresiones Sexuales y Violencia de Género, A.D.A.V.A.S.) focus on the prevention of sexual and domestic abuse through educating children and adolescents to gender equality. Furthermore, support projects have been implemented for the social and emotional recovery of women who have survived domestic violence.

In the UK, domestic violence is a fairly widespread phenomenon: $27.1 \%$ of women and $13.2 \%$ of men experienced any domestic abuse since the age of 16 (Office for National Statistics, 2016). This has a negative impact on children, families and on society throughout, with high human and economic costs. The National Institute for Health and Care Excellence (NICE) has recently published (2014) a list of recommendations including the creation of a protected environment for revealing domestic violence and abuse, with the presence of qualified personnel with frontline experience in dealing with cases of domestic violence, that may indicate the root for referral to specialized treatment. NICE recommends the assessment of high-risk environments such as prenatal services, services for sexual health, alcohol and drug abuse when associated to domestic violence. However, it acknowledges that there is no sufficient proof for the universal screening of healthcare facilities.

In the UK, as well as in Canada and in the USA, the first therapeutic programs for abusers are compulsory today. The primary work method consists in a pro-feminist approach, emphasizing the responsibility and violence as associated to male strategies of power and control (Adams, 1989; Pence \& Paymar, 1993). Generally, a combination of approaches is put into place, concerning the psychological aspects of male violence and the deconstruction of violence, as an alternative behavioral pattern. Psycho-educational programs are included in manuals and imply a certain degree of re-education (for example the Duluth model). In countries such as Hungary and Greece projects are aimed at the elaboration of recommendations and best practices. Specifically, for what concerns the management of support groups for women who have suffered abuse, a section is dedicated to creating awareness 
among women (both separated from their abusing partner or still with him) concerning the effects of domestic violence on their children, and provides them with techniques for supporting their children.

Everyone recognizes the importance of realizing efficacious intervention strategies to be used for all members of the family: perpetrators of violence, their partners, and children exposed to IPV (Stover, Meadows, \& Kaufman, 2009). The study intends to analyze in depth the interventions and make a distinction between those aimed at perpetrators, victims, and the couple.

\section{Interventions for perpetrators}

Perpetrators of IPV are very difficult to treat, especially if they have complicated life histories and mental disorders. Many have witnessed family violence or were victims of abuse as children (Delsol \& Margolin, 2004; Gortner, Gollan, \& Jacobson, 1997) and often present personality pathologies (notably, borderline, narcissistic, and antisocial; e.g. Fowler \& Westen, 2011; HoltzworthMunroe \& Stuart, 1994; Jackson, Sippel, Mota, Whalen, Schumacher, 2015; Mauricio, Tein, \& Lopez, 2007; Porcerelli, Cogan, \& Hibbard, 2004; Saunders, 1992) and substance abuse problems (e.g., Kraanen, Vedel, Scholing, Emmelkamp, 2014; Singh, Tolman, Walton, Chermack, Cunningham, 2014). Despite the frequent co-occurrence of the perpetrator's own trauma history, personality disorders, and substance abuse, it is important to note that incorporation of more structured and specific intervention strategies of these aspects is not typically targeted into IPV current treatments, limiting their effectiveness.

A first intervention strategy for batterers is mandatory arrest. Despite declarations that arrest followed by courtordered treatment offers great hope and potential for breaking the destructive cycle of violence (U.S. Attorney General, 1984, p. 48), there is a low number of empirical evidence that this kind of treatment is effective in reducing recidivism of family violence to any meaningful degree (Maxwell, Garner, \& Fagan, 2001). Results are however different depending on whether we look at the police reports or at the reports of the victims. Mandatory arrest was associated with lower rates of recidivism compared to enforced separation and mediation, but not compared to non-arrest according to victim reports (Stover, Meadows, \& Kaufman, 2009).

Aside from mandatory arrest, the most frequently used intervention strategies for IPV are feminist sociocultural (Duluth model; Pence \& Paymar, 1993) and cognitive-behavioral therapy (CBT; Murphy \& Eckhardt, 2005) administered in all male groups. Recently, it has become common practice to combine elements of these two approaches (Babcock, Green, \& Robie, 2004).

Since IPV is seen as an outgrowth of normal male behavior and socialization, programs rely on a gender re-education model rather than psychotherapeutic models that identify individual causes of violence such as behavioral deficits, trauma, or psychopathology (Eckhardt et al., 2013). Traditional IPV interventions presume that exposing patriarchal/misogynistic attitudes, encouraging accountability and personal responsibility for coercive tactics in relationships, and promoting gender-egalitarian attitudes and behaviors best achieve violence reduction. Despite extensive debate on the core assumptions of this approach (e.g., Dutton \& Nicholls, 2005; Straus, 2011), most existing intervention programs as well as state laws and guidelines that regulate IPV intervention espouse key aspects of feminist perspectives on IPV etiology and intervention (Maiuro \& Eberle, 2008).

The Duluth model (Pence, \& Paymar, 1993) is a psycho-educational treatment approach for perpetrators of IPV, developed by the Duluth Domestic Abuse Intervention Project. It is based on a feminist theory positing that domestic violence is the result of patriarchal ideology in which men are encouraged and expected to control their partners through the power and control wheel (this tool has been utilized by advocates as a way to help explain the different tactics that perpetrators use against their partners, in the context of a larger construct of socialization). This program, developed from a social work perspective, typically eschews Diagnostic and Statistical Manual of Mental Disorders (DSM)-type diagnoses and does not consider the intervention to be therapy. According to this specific tactic, men use intimidation, male privilege, isolation, emotional and economic abuse, and violence to gain and maintain power over a victim. The Duluth model is implemented in many intervention programs with batterers, lasting 8-36 weeks, and emphasizes re-education of men with the goal of shifting beliefs and behaviors toward a more egalitarian orientation with women (Lawson, Kellam, Quinn, \& Malnar 2012). The feminist Duluthtype model remains the unchallenged treatment of choice for most communities.

Another approach for IPV perpetrators is group CBT. It focuses on learning non-violence (Adams, 1988) and provides skills training (e.g., anger management, communication skills, assertiveness, relaxation techniques) to promote awareness of alternatives to violent behavior. Other authors (Johnson \& Zlontnick, 2009) used a CBT approach to promote client safety, empowerment, and interpersonal relationships. The labels of these intervention models are often misleading. Some CBT groups are not strictly cognitive or behavioral, as they address emotional components of violence, such as empathy and jealousy (Dunford, 2000). Most modern cognitive-behavioral groups also usually address perpetrator attitudes and values regarding women, and the use of violence toward women. To the extent that CBT groups address patriarchal attitudes, and Duluth model groups address the learned and reinforced aspects of violence, any distinction between CBT and Duluth model groups becomes increasingly unclear (Babcock, Green, \& Robie, 2004). An evident limit is the lack of methodologically appropriate 
studies that go beyond the differences between these two approaches. There are very few methodologically adequate studies of interventions for perpetrators effectiveness. As noted by reviewers of this literature (e.g., Kjeken et al., 2011), almost all effectiveness studies have been conducted in North America, they typically involve a relatively small number of participants, and make limited use of randomized designs (Eckhardt et al., 2013).

Overall, group treatments for IPV batterers have meagre effects on the cycle of violence. Most studies, regardless of intervention strategies (mandatory arrest, Duluth model group treatment, CBT), report that approximately one in three cases will have a new episode of IPV within 6 months based on the victim's reports. Moreover, this rate must be accepted with caution given the high attrition in victim reports across studies (Stover et al., 2009). Clinicians and researchers hold a less than optimistic view about the effectiveness of current psychosocial interventions for IPV (for an alternative perspective see Gondolf, 2002) highlighting the need for more effective treatments (e.g. Lawson et al., 2012).

\section{Interventions for women victims of intimate partner violence}

Numerous IPV interventions are centered on victims of batterers. The research literature on interventions for survivors of IPV provides considerable encouragement regarding the use of counselling and structured therapy in reducing negative effects of abuse, including post-traumatic stress disorder (PTSD) symptoms and depression (Eckhardt et al., 2013). Victims are at risk for a wide range of negative effects that go beyond immediate physical injuries and include a variety of stress-related psychiatric pathologies, such as depression, anxiety, and PTSD (Dutton et al., 2006). Despite the lack of homogeneous results due to variability in samples (size, context, etc.), several authors seem to highlight the frequent association between IPV and maladaptive patterns of personality (Cogan \& Porcerelli 1996; Gellen, Hoffman, Jones, \& Stone 1984; Khan, Welch, \& Zillmer 1993; Palau 1981).

Interventions can concern different aspects of IPV: safety, lifestyle, short-term consequences, trauma processing, treatment implications, re-victimization, etc. Brief intervention programs (that consist in three or fewer hours of contact) vary considerably in context (mostly medical), focus, and intensity of contact. In medical contexts, prenatal care clinics are the most common setting. Other interventions are developed in family violence legal clinics, services associated with community policing, or university settings with volunteers from the community.

Medical interventions can address safety behaviors and resource use, such as communities, shelter and shelter-based counselling services (e.g., Muelleman \& Feighny, 1999); others provide information and referrals about health care, with no explicit protocol specified (MacMillan et al., 2009). Interventions conducted in legal clinics or as an adjunct to community policing provided IPV victims with support and advocacy (Beeble, Bybee, Sullivan, \& Adams, 2009). For instance, the Moms' Empowerment Program (Graham-Bermann, 2000; GrahamBermann \& Miller, 2013, 2015) is a group intervention for women victims of IPV, which offers knowledge on how to solve conflicts, assertive communication, stress management, and control of emotions. The final meetings of the intervention tend to further develop social support of women and broaden the knowledge of available resources in the community. The participants are never actively encouraged to end their relationship; on the contrary, women are provided with support and empowerment. As regards the limits of this intervention, although the adherence to the treatment manual was discussed on a weekly basis, this was not empirically assessed, and there has been no follow up. Finally, the data on victimization is provided by self-reports.

In opposition to brief interventions, a wide array of treatments for IPV victims includes extended counselling, therapeutic, and advocacy programs. They are mostly conducted within the context of shelter or after discharge of women from it. Structured interventions using cognitive-behavioral strategies have been quite efficacious in this regard (Johnson, Zlotnick, \& Perez, 2011; Kubany, Hill, \& Owens, 2003; Kubany et al., 2004). CBT is commonly used in working with violence survivors. Notably, there are two main programs that represent specific variations of CBT approach designed to this target population: i) the Cognitive Trauma Therapy for Battered Women (CTT-BW; Kubany et al., 2003, 2004); and ii) the Helping to Overcome PTSD through Empowerment (HOPE) program (Johnson et al., 2011). Kubany and colleagues' CTT$\mathrm{BW}$ is a cognitive trauma therapy for women with PTSD that incorporates many features from standard CBT therapies for PTSD, including education, stress management, exposure therapy, and restructuring of guilt and shamerelated cognitions. Johnson and colleagues' HOPE program is a CBT-based intervention for women in shelter that addresses safety issues, PTSD symptoms, quality-oflife concerns, and post-shelter goals. In some clinical trials, CTT-BW has had excellent effects, leading to very substantial and significant reductions in PTSD diagnosis, PTSD symptoms, depressive symptoms, and trauma-related guilt (Iverson et al., 2011). The HOPE's effects showed meaningful decrease of depression level and an increase of social support. The main limitation of evidence for CTT-BW thus far are that its effects have not been independently replicated by a different research team, and maintenance of gains beyond 6 months has not yet been studied.

Some authors (Cort et al., 2014; Zlotnick, Capezza, \& Parker, 2011) have also explored the preliminary effectiveness of an interpersonal therapy (IPT) for women victims of IPV and the results indicate that IPT can be effective in reducing the severity of symptoms of depression among 
women with a background of IPV. It has been shown that also symptoms of PTSD can be reduced to non-clinical levels (Falsetti, Resnick, Resick, \& Kilpatrick, 1993). Groups using IPT for women victims of IPV have proven to be effective also in facilitating opportunities to develop a series of social skills (MacKenzie \& Grabovac, 2001). Furthermore, longitudinal assessments of the effectiveness of IPT indicate that persistent social maladjustment increases the risk of depression relapse (Rodriguez, Bruce, Pagano, \& Keller, 2005). The limitations of this study are due to the absence of a control group; moreover, the study was conducted on a small sample of women with a low-income who presented symptoms of depression that went from severe to moderate.

Aside from CBT, several diverse sets of interventions have been developed, including a culturally informed empowerment group therapy (e.g., for African American survivors of IPV; Kaslow et al., 2010), social support groups (e.g, Constantino, Kim, \& Crane, 2005), feminist-oriented counselling and grief resolution counselling (Mancoske, Standifer, \& Cauley, 1994), battered women shelters that are based on the relationship between women and implying a positive mirroring of their gender, that is a mutual recognition of their skills and value and a reference to the project force to counter the powerlessness that women can experience in these situations (Molfino, 2014), and so on. They seem to show some positive effects on the psychological distress of IPV victims.

Other notable types of intervention for IPV women are represented by the post-shelter community advocacy programs: trained paraprofessionals were assigned to provide community and in-home advocacy services for battered women. These programs have shown considerable promise in enhancing wellbeing and quality of life (Sullivan \& Bybee, 1999; Sullivan, Bybee, \& Allen, 2002; Rivas et al., 2015), and in assisting battered women to make the transition from shelter to independent life in the community.

\section{Couple}

Finally, there are couple treatments for IPV. Despite limited evidence, it seems that this approach is more effective in reducing IPV recidivism for men with comorbid substance abuse and partner violence (Fals-Stewart, Kashdan, O'Farrell, \& Birchler 2002; Lawson et al., 2012). Although some of the individual interventions available have shown promising effects, it may be difficult to deliver these interventions in settings where funding or staffs is limited, such as in shelters or community centers.

Miller et al. (2014) have shown that there have been few RCT interventions testing the efficacy of therapeutic intervention as a way of reducing women's exposure to IPV. Although these studies offer valuable information about brief interventions that may provide some shortterm protection against violence, it is clear that more work needs to be done to promote permanent and positive change in the lives of women exposed to IPV. One reason for a lack of longstanding effect in past studies might be the general neglect of women's mental health difficulties after their experiences of abuse. For example, recent research has found that women's PTSD symptoms after exposure to IPV predict future re-victimization (Kuijpers, van der Knaap, \& Winkel, 2012).

In the light of the interventions treated, we can observe how the treatments used for women victims of IPV are part of a wide range that goes from specific interventions on the woman victim of IPV to an intervention in the family context, which focus in particular on the perpetrators. Nevertheless, the drop out rates are significant. Most of the treatments considered have shown limited effects on repeated violence, especially in the light of the lack of evidence, which would allow to verity the effectiveness of these treatments. The rates of recurrence, in the case of the victims and perpetrators, are of about $30 \%$ in the first 6 months, regardless of the type of intervention adopted (Stover et al., 2009). Shelter-advocacy approaches are the most common form of treatment; however, rates of new incidents of IPV range from 31 to $44 \%$ when women are assessed six months to three years post-treatment. In one of the only long-term randomized studies of shelter-advocacy interventions, Sullivan and colleagues followed 284 women who participated in an intensive 10 -week post-shelter counselling and advocacy program. Rates of physical violence in the treatment group were lower than the controls at the two-year follow-up but not when a subset of women was assessed at three years. Group differences emerged for quality of life and social support at the two- and three-year follow-up, but not for depression or psychological abuse (Bybee \& Sullivan, 2005; Sullivan \& Bybee, 1999).

Psychodynamic and cognitive psychotherapy approaches, alternatively, target mental health symptoms more directly. One empirical study of brief psychodynamic therapy among trauma victims found that this treatment was associated with a greater reduction in avoidance symptoms related to trauma relative to other treatments; however, an IPV population was not used (Brom, Kleber, \& Defares, 1989).

\section{Discussion}

These studies highlighted the limits of prevention and treatment of women suffering from IPV. Consequently, it is important to identify a series of steps to build up a strategy, which may integrate the work already being carried out and its strong points, and develop a model for treatment.

We believe it is necessary to develop articulate intervention programs able to evaluate the way women undergo IPV psychological functioning, so as to identify a specific model which may - on the one hand - investigate the specific characteristics of the psychotherapeutic process associated to the treatment of women victims of IPV, and - on the other hand - validate a general model, 
empirically based, for the psychotherapeutic treatment of these women, with the aim of preventing relapses.

Many of the studies presented do not allow making a clear distinction between psychological interventions and psychological support interventions; some of these present various strong points, but in many cases they are methodologically limited and the quality of scientific evidence is low or moderate. Furthermore, there seems to be no clear distinction between psychological problems, and psychological and social maladjustment, in that if even the latter were to be caused by and aggravated by psychopathological problems, the intervention might not be effective and the subject would risk a relapse.

In Anglo Saxon countries and at an international level, most protocols and policies concerning domestic violence advocate use of the Duluth Model. This model uses a feminist informed, gender-based analysis of domestic violence, making use of psycho-educational techniques. It focuses on male perpetrators and female victims. It does not advocate relationship counselling, and directs men to take total responsibility for the violent relationship. Generally, these models have received criticism because of lack of research evidence, and because they pay little attention to bi-directional violence or women as perpetrators and even less to gay and lesbian domestic violence.

Therapeutic interventions instead have received longstanding criticism due to their tendency to consider violence as a symptom of problems rooted in childhood experiences, and the lack of importance given to gender and therefore to a socio political reading of the phenomena (psychodynamic approach) or because they appear to resolve themselves in a superficial acquisition of techniques that do not produce any true change (cognitive-behavioral approach).

Despite some useful recommendations for psychotherapists who treat and assess the conditions of women suffering from IPV (Bogat et al., 2013), it is important for the clinician to continue to be informed on domestic violence, because women are often reluctant to talk about the violence they are subject to soon after it occurs, and when they do they often tend to minimize it.

To this regard it seems necessary to investigate the distinction between a social and relational phenomenon (IPV) and the psychopathological problems linked to IPV. The treatment, by definition, targets psychological problems, so to consider IPV as a diagnostic population is wrong because here we are not dealing with pathology but with functioning strategies that can represent risk factors or contribute to create significant impairments in different life domains and distress.

It would be necessary and useful to have access to more rigorous studies on personality traits in women victims of violence that allow to achieve valid and reliable results through multi-method and multi-informant methodologies, given that the empirical investigations reported in literature make use for the most part of self re- port tools (Gellen, Hoffman, Jones, Stone, \& 1984; Khan et al., 1993; Palau, 1981; Rhodes, 1992; Rosewater, 1988). Although, of course, self-report measures present the advantage of being cheap and easy to administer, they present various limitations based on overreliance on a single informant (Babcock, Costa, Green, \& Eckhardt, 2004; Bornstein, 2006; Campbell et al., 1995). Another important aspect that must be stressed is the need to carry out an in depth study of the previous developments that characterize the history of women who are victims of violence. Exposure to family violence as a child is a strong risk factor for both perpetration and victimization of IPV (Colman \& Widom, 2004; Widom, Czaja, \& Dutton, 2008).

\section{Conclusions}

To understand the history of violence of women is important for various reasons. Obviously the more a woman has been subject to one or more violent relationships, the more difficult the therapeutic treatment will be, a treatment that is necessary to break away from such relationships. To understand the history of these women and to carry out an in depth study on how these factors may influence the development of a condition is fundamental because it would help to view these women not just as passive victims, and also to avoid the mechanism of viewing them as women who are asking for it.

\section{References}

Adams, D. (1988). Treatment models of men who batter: a profeminist analysis. In: K. Yllö \& M. Bograd (Eds.), Feminist perspectives on wife abuse (pp. 176-199). Thousand Oaks, CA: Sage.

Adams, D. (1989). Feminist-based interventions for battering men. In: P.L. Caesar \& L.K. Hamberger (Eds.), Treating men who batter: theory, practice and programs (pp. 3-23). New York, NY: Springer Publishing.

American Psychiatric Association (2013). Diagnostic and statistical manual of mental disorders (5th ed.). Washington, DC: American Psychiatric Association.

Babcock, J.C., Costa, D.M., Green, C.E., \& Eckhardt, C.I. (2004). What situations induce intimate partner violence? A reliability and validity study of the Proximal Antecedents to Violent Episodes (PAVE) scale. Journal of Family Psychology, 18(3), 433-442. doi: 10.1037/0893-3200.18.3.433

Babcock, J.C., Green, C.E., \& Robie, C. (2004). Does batterers' treatment work? A meta-analytic review of domestic violence treatment. Clinical Psychology Review, 23(8), 10231053. doi: 10.1016/j.annepidem.2008.02.005

Bair-Merritt, M.H., Holmes, W.C., Holmes, J.H., Feinstein, J., \& Feudtner C. (2008). Does intimate partner violence epidemiology differ between homes with and without children? A population-based study of annual prevalence and associated risk factors. Journal of Family Violence, 23, 325-332. doi:10.1007/s10896-008-9154-y

Beeble, M.L., Bybee, D., Sullivan, C.M., \& Adams, A.E. (2009). Main, mediating, and moderating effects of social support 
on the well-being of survivors of intimate partner violence across 2 years. Journal of Consulting and Clinical Psychology, 77(4), 718-729. doi:10.1037/a0016140

Bensley, L., Van Eenwyk, J., \& Wynkoop Simmons, K. (2003). Childhood family violence history and women's risk for intimate partner violence and poor health. American Journal of Preventive Medicine, 25, 38-44. doi:10.1016/S07493797(03)00094-1

Black, M.C., Basile, K.C., Breiding, M.J., Smith, S.G., Walters, M.L., Merrick, M.T., Chen, J., \& Stevens, M.R. (2011). The National Intimate Partner and Sexual Violence Survey (NISVS): 2010 summary report. Atlanta, GA: National Center for Injury Prevention and Control, Centers for Disease Control and Prevention.

Bogat, G.A., Garcia, A.M., \& Levendosky, A.A. (2013). Assessment and psychotherapy with women experiencing intimate partner violence: integrating research and practice. Psychodynamic Psychiatry, 41, 189-217. doi:10.1521/pdps.2013. 41.2.189

Bornstein, R.F. (2006). The complex relationship between dependency and domestic violence: converging psychological factors and social forces. American Psychologist, 61(6), 595-606. doi:10.1037/0003-066X.61.6.595

Breiding, M.J., Black, M.C., \& Ryan, G.W. (2008). Chronic disease and health risk behaviors associated with intimate partner violence - 18 U.S. States/Territories, 2005. Annals of Epidemiology, 18, 538-544. doi: http://dx.doi.org/10.1016/j. annepidem.2008.02.005

Brom, D., Kleber, R.J., \& Defares, P.B. (1989). Brief psychotherapy for posttraumatic stress disorders. Journal of Consulting and Clinical Psychology, 57(5), 607-612. doi: 10.1037/0022-006X.57.5.607

Bybee, D. \& Sullivan, C.M. (2005). Predicting re-victimization of battered women 3 years after exiting a shelter program. American Journal of Community Psychology, 36, 85-96. doi:10.1007/s10464-005-6234-5

Campbell, R., Sullivan, C.M., \& Davidson, W.S. (1995). Women who use domestic violence shelters: changes in depression over time. Psychology of Women Quarterly, 19, 237-255. doi:10.1111/j.1471-6402.1995.tb00290.x

Capaldi, D.M., Knoble, N.B., Shortt, J.W., \& Kim, H.K. (2012). A systematic review of risk factors for intimate partner violence. Partner Abuse, 3, 231-280. doi:10.1891/1946-6560. 3.2.231

Carter, L., Weithorn, L. \& Behrman, R. (1999). Domestic violence and children: analysis and recommendations. The Future of children: Domestic Violence and Children, 9(3), 1-20.

Classen, C.C., Palesh, O.G., \& Aggarwal, R. (2005). Sexual revictimization: a review of the empirical literature, $6(2), 103-$ 129. doi: $10.1177 / 1524838005275087$

Cogan, R., \& Porcerelli, J.H. (1996). Object relations in abusive partner relationships: an empirical investigation. Journal of Personality Assessment, 66, 106-115. doi: http://dx.doi.org/ $10.1207 /$ s15327752jpa6601 8

Colman, R.C., \& Widom, C.S. (2004). Childhood abuse and neglect and adult intimate relationships: a prospective study. Child Abuse and Neglect, 28, 1133-1151. doi:10.1016/j.chiabu.2004.02.005

Constantino, R., Kim ,Y., \& Crane, P.A. (2005). Effects of a social support intervention on health outcomes in residents of a domestic violence shelter: a pilot study. Issues in Mental Health Nursing2005, 26(6), 575-590. doi:10.1080/01612 840590959416
Cort, N.A., Cerulli, C., Poleshuck, E.L., Bellenger, K.M., Xia, Y., Tu, X., Mazzotta, C.M., \& Talbot, N.L. (2014). Interpersonal psychotherapy for depressed women with histories of intimate partner violence. Psychological Trauma: Theory, Research, Practice, and Policy, 6(6), 700-707. doi:10.1037/ a0037361

Dahlberg, L.L., \& Krug, E.G. (2002). Violence: a global public health problem. In: E.G. Krug, L.L. Dahlberg, J.A. Mercy, A.B. Zwi, \& R. Lozano (Eds.), World report on violence and health (pp. 3-21). Geneva, Switzerland: World Health Organization.

Delsol, C., \& Margolin, G. (2004). The role of family-of-origin violence in men's marital violence perpetration. Clinical Psychology Review, 24(1), 99-122. doi:10.1016/j.cpr.2003. 12.001

Desai, S., Arias, I., Thompson, M.P., \& Basile, K.C. (2002). Childhood victimization and subsequent adult revictimization assessed in a nationally representative sample of women and men. Violence and Victims, 17(6), 639-653. doi:10.1891/vivi.17.6.639.33725

Devries, K.M., Mak, J.Y., Bacchus, L.J., Child, J.J., Falder, G., Petzold, M., Astbury, J., \& Watts, C.H. (2013). Intimate partner violence and incident depressive symptoms and suicide attempts: a systematic review of longitudinal studies. PLoS Medicine, 10(5): e1001439. doi:10.1371/journal.pmed. 1001439

Dunford, F.W. (2000). The San Diego Navy Experiment: an assessment of interventions for men who assault their wives. Journal of Consulting and Clinical Psychology, 68(3), 468476. doi:10.1037/0022-006X.68.3.468

Dutton, D.G. (2006). Rethinking domestic violence. Vancouver: University of British Columbia Press.

Dutton, D.G., \& Nicholls, T.L. (2005). The gender paradigm in domestic violence research and theory: part 1 . The conflict of theory and data. Aggression and Violent Behavior, 10, 680-714. doi:10.1016/j.avb.2005.02.001

Dutton, M.A., Green, B.L., Kaltman, S.I., Roesch, D.M., Zeffiro, T.A., \& Krause, E.D. (2006). Intimate partner violence, PTSD, and adverse health outcomes. Journal of Interpersonal Violence, 21, 955-968. doi:10.1177/0886260506289178

Eckhardt, C.I., Murphy, C.M., \& Sprunger, J. (2014). The effectiveness of intervention programs for perpetrators of intimate partner abuse. Psychiatric Times, 31(8), 29-32. doi: 10.1891/1946-6560.4.2.196

Eckhardt, C.I., Murphy, C.M., Whitaker, D.J., Sprunger, J., Dykstra, R., \& Woodard, K. (2013). The effectiveness of intervention programs for perpetrators and victims of intimate partner violence. Partner Abuse, 4(2), 196-231. doi:10.1891/ 1946-6560.4.2.196

Ehrensaft, M.K., Moffitt, T.E., \& Caspi, A. (2006). Is domestic violence followed by an increased risk of psychiatric disorders among women but not among men? A longitudinal cohort study. American Journal of Psychiatry, 163(5), 885892. doi: 10.1176/ajp.2006.163.5.885

Falsetti, S.A., Resnick, H.S., Resick, P.A., \& Kilpatrick, D.G. (1993). The modified PTSD symptom scale: a brief self-report measure of posttraumatic stress disorder. The Behavior Therapist, 16, 161-162. doi:10.1037/t05175-000

Fals-Stewart, W., Kashdan, T.B., O'Farrell, T.J., \& Birchler, G.R. (2002). Behavioral couples therapy for drug-abusing patients: effects on partner violence. Journal of Substance Abuse Treatment, 22(2), 87-96. doi:10.1016/S0740-5472 (01)00218-5 
Fonagy, P. (1999). Male perpetrators of violence against women: an attachment theory perspective. Journal of Applied Psychoanalytic Studies, 1, 7-27. doi:10.1023/A:1023074023087

Fowler, K.A., \& Westen, D. (2011). Subtyping male perpetrators of intimate partner violence. Journal of Interpersonal Violence, 26(4), 607-639. doi:10.1177/0886260510365853

Gellen, M.I., Hoffman, R.A., Jones, M., \& Stone, M. (1984). Abused and non-abused women: MMPI profile differences. The Personnel and Guidance Journal, 6, 601-603. doi: 10.1111/j.2164-4918.1984.tb00134.x

Golding, J.M. (1999). Intimate partner violence as a risk factor for mental disorders: a meta-analysis. Journal of Family Violence, 14(2), 99-132. doi:10.1023/A:1022079418229

Gondolf, E. (2002). Service barriers for battered women with male partners in batterer programs. Journal of Interpersonal Violence, 17, 217-227. doi:10.1177/0886260502017002007

Gortner, E.T., Gollan, J.K., \& Jacobson, N.S. (1997). Couples therapy. In: A. Tasman, J. Kay, \& J.A. Lieberman (Eds.), Psychiatry (pp. 1452-1474). Philadelphia, PA: WB Saunders Company.

Graham-Bermann, S.A. (2000). Evaluating interventions for children exposed to family violence. Journal of Aggression, Maltreatment \& Trauma, 4(1), 191-216. doi:10.1300/J146v04 n01_09

Graham-Bermann, S.A., \& Miller, L.E. (2013). Intervention to reduce traumatic stress following intimate partner violence: an efficacy trial of the Moms' Empowerment Program (MEP). Psychodynamic Psychiatry, 41(2), 329-349, doi: 10.1521/pdps.2013.41.2.329

Graham-Bermann, S.A., \& Miller, L.E. (2015). Communitybased intervention for women exposed to intimate partner violence: a randomized control trial. Journal of Family Psychology, 29(4), 537-547. doi:10.1037/fam0000091

Heise, L.L. (1998). Violence against women: an integrated, ecological framework. Violence Against Women, 4(3), 262-290. doi:10.1177/1077801298004003002

Holtzworth-Munroe, A., \& Stuart, G.L. (1994). Typologies of male batterers: three subtypes and the differences among them. Psychological Bulletin, 116(3), 476-497. doi: http:// dx.doi.org/10.1037/0033-2909.116.3.476

Iverson, K.M., Gradus, J.L., Resick, P.A., Suvak, M.K., Smith, K.F., \& Monson, C.M. (2011). Cognitive-behavioral therapy for PTSD and depression symptoms reduces risk for future intimate partner violence among interpersonal trauma survivors. Journal of Consulting and Clinical Psychology, 79(2), 193-202. doi:10.1037/a0022512

Jackson, M.A., Sippel, L.M., Mota, N., Whalen, D., \& Schumacher, J.A. (2015). Borderline personality disorder and related constructs as risk factors for intimate partner violence perpetration. Aggression and Violent Behavior, 24, 95-106. doi:10.1016/j.avb.2015.04.015

Johnson, D.M., \& Zlotnick, C. (2009). HOPE for battered women with PTSD in domestic violence shelters. Professional Psychology: Research and Practice, 40, 234-241. doi:10.1037/a0012519

Johnson, D.M., Zlotnick, C., \& Perez, S. (2011). Cognitive behavioral treatment of PTSD in residents of battered women's shelters: results of a randomized clinical trial. Journal of Consulting and Clinical Psychology, 79, 542-551. doi:10. 1037/a0023822

Kaslow, N.J., Leiner, A.S., Reviere, S.L., Jackson, E., Bethea, K., Bhaju, J., ..., Thompson, M.P. (2010). Suicidal, abused African American women's response to a culturally-in- formed intervention. Journal of Consulting and Clinical Psychology, 78(4), 449-458. doi: 10.1037/a0019692

Kessler, R.C., McGonagle, K.A., Zhao, S., Nelson, C.B., Hughes, M., Eshleman, S., ..., Kendler, K.S. (1994). Lifetime and 12month prevalence of DSM-III-R psychiatric disorders in the United States. Results from the National Comorbidity Survey. Archives of General Psychiatry, 51(1), 8-19.

Khalifeh, H., Oram, S., Trevillion, K., Johnson, S., \& Howard, L.M. (2015). Recent intimate partner violence among people with chronic mental illness: findings from a national crosssectional survey. The British Journal of Psychiatry, 207, 207-212. doi:10.1192/bjp.bp.114.144899

Khan, F.I., Welch, T.L., \& Zillmer, E.A. (1993). MMPI-2 profiles of battered women in transition. Journal of Personality Assessment, 60, 100-111.

Kjeken, I., Smedslund, G., Moe, R.H., Slatkowsky-Christensen, B., Uhlig, T., \& Hagen, K.B. (2011). Systematic review of design and effects of splints and exercise programs in hand osteoarthritis. Arthritis Care \& Research, 63(6), 834-848. doi:10.1002/acr.20427

Kraanen, F.L., Vedel, E., Scholing, A., \& Emmelkamp, P.M. (2014). Prediction of intimate partner violence by type of substance use disorder. Journal of Substance Abuse Treatment, 46(4), 532-539. doi: 10.1016/j.jsat.2013.10.010

Kubany, E.S., Hill, E.E., \& Owens, J.A. (2003). Cognitive trauma therapy for battered women with PTSD: preliminary findings. Journal of Traumatic Stress, 16, 81-91. doi: 10.1023/A:1022019629803

Kubany, E.S., Hill, E.E., Owens, J.A., Iannce-Spencer, C., McCaig, M.A., Tremayne, K.J., \& Williams, P.L. (2004). Cognitive trauma therapy for battered women with PTSD (CTT-BW). Journal of Consulting and Clinical Psychology, 72, 3-18. doi:10.1037/0022-006X.72.1.3

Kuijpers, K.F., van der Knaap, L.M., \& Winkel, F.W. (2012). PTSD symptoms as risk factors for intimate partner violence revictimization and the mediating role of victims' violent behavior. Journal of Traumatic Stress, 25(2), 179-186. doi: $10.1002 /$ jts. 21676

Lawrence, E., Orengo, R., Langer, A., \& Brock, R.L. (2012). The impact and consequences of partner abuse on partners. Partner Abuse, 3, 406-428. doi:10.1891/1946-6560.3.4.406

Lawson, D.M., Kellam, M., Quinn, J., \& Malnar, S.G. (2012). Integrated cognitive-behavioral and psychodynamic psychotherapy for intimate partner violent men. Psychotherapy, 49(2), 190-201. doi:10.1037/a0028255

Lila, M., Catalá, A., Conchell, R. García, A., Lorenzo, M.V., Pedrón, V., \& Terreros, E. (2010). Una experiencia de investigación, formación e intervención con hombres penados por violencia contra la mujer en la Universidad de Valencia: Programa Contexto [A research, training and intervention experience at University of Valencia with men convicted of violence against women: Programa Contexto]. Psychosocial Intervention, 19, 167-179. doi:10.5093/in2010v19n2a8

MacKenzie, K.R., \& Grabovac, A.D. (2001). Interpersonal Psychotherapy Group (IPT-G) for depression. The Journal of Psychotherapy Practice and Research, 10(1), 46-51.

MacMillan, H.L., Wathen, C.N., Jamieson, E., Boyle, M.H., Shannon, H.S., Ford-Gilboe, M., ... McNutt, L. (2009). Screening for intimate partner violence in health care settings: a randomized trial. JAMA: Journal of the American Medical Association, 302(5), 493-501. doi:10.1001/jama. 2009.1089

Maiuro, R.D., Eberle, J.A. (2008). State standards for domestic 
violence perpetrator treatment: current status, trends, and recommendations. Violence and Victims, 23(2), 133-155. doi: http://dx.doi.org/10.1891/0886-6708.23.2.133

Mancoske, R.J., Standifer, D., \& Cauley, C. (1994). The effectiveness of brief counseling services for battered women. Research on Social Work Practice, 4(1), 53-63. doi:http://dx.doi.org/10.1177/104973159400400105

Mauricio, A.M., Tein, J., \& Lopez, F.G. (2007). Borderline and antisocial personality scores as mediators between attachment and intimate partner violence. Violence and Victims, 22(2), 139-157. doi:10.1891/088667007780477339

Maxwell, C.D., Garner, J.H., \& Fagan, J.A. (2001). The effects of arrest on intimate partner violence: new evidence from the spouse assault replication program. Washington, DC: US Department of Justice, Office of Justice Programs.

Merlo, J. (2011). Contextual influences on the individual life course: building a research framework for social epidemiology. Psychosocial Intervention, 20, 109-118. doi:10.5093/ in2011v20n1a9

Miller, L.E., Howell, K.H., \& Graham-Bermann, S.A. (2014). The effect of an evidence-based intervention on women's exposure to intimate partner violence. The American Journal of Orthopsychiatry, 84(4), 321.328. doi:10.1037/h0099840

Miller, T.R., Cohen, M.A., \& Rossman, S.B. (1993). Victim costs of violent crime and resulting injuries. Health affairs (Project Hope), 12(4), 186-197. doi:10.1377/hlthaff.12. 4.186

Molfino, F. (2014). Storia dei gruppi: dall'autocoscienza femminista al centro antiviolenza. In: D. Bolelli (Ed.), Per le donne che aiutano le donne. La violenza tra i sessi e le generazioni. Pisa: Associazione Casa della Donna.

Muelleman, R.L., \& Feighny, K.M. (1999). Effects of an emergency department-based advocacy program for battered women on community resource utilization. Annals of Emergency Medicine, 33(1), 62-6.

Murphy, C.M., \& Eckhardt, C.I. (2005). Treating the abusive partner: an individualized cognitive- behavioral approach. New York, NY: Guilford Press.

National Institute for Health and Care Excellence (2014). Domestic violence and abuse: how health services, social care and the organisations they work with can respond effectively. Available from: https://www.nice.org.uk/guidance/ph50

Nelson, H.D., Bougatsos, C., Blazina, I. (2012). Screening women for intimate partner violence: a systematic review to update the US Preventive Services Task Force recommendation. Annals of Internal Medicine, 156, 796-808. doi:10.7326/0003-4819-156-11-201206050-00447

Office for National Statistics (2016). Crime survey for England and Wales. Available from: https://www.ons.gov.uk/

Palau, N. (1981). Battered women: a homogeneous group? Theoretical considerations and MMPI data interpretation. Paper presented at the annual meeting of the American Psychological Association, Los Angeles, CA, USA.

Pence, E., \& Paymar, M. (1993). Education groups for men who batter: the Duluth model. New York, NY: Springer.

Porcerelli, J.H., Cogan, R., \& Hibbard, S. (2004). Personality characteristics of partner violent men: a Q-sort approach. Journal of Personality Disorders, 18(2), 151-162. doi: 10.1521/pedi.18.2.151.32776

Rhodes, N.R. (1992). Comparison of MMPI Psychopathic Deviate scores of battered and nonbattered women. Journal of Family Violence, 7(4), 297-307. doi:10.1007/BF00994620

Rivas, C., Ramsay, J., Sadowski, L., Davidson, L.L., Dunne, D.,
Eldridge, S., ... Feder, G. (2015). Advocacy interventions to reduce or eliminate violence and promote the physical and psychosocial well-being of women who experience intimate partner abuse. The Cochrane Database of Systematic Reviews, 12, CD005043. doi:10.1002/14651858.CD005043.pub3

Rodriguez, B.F., Bruce, S.E., Pagano, M.E., \& Keller, M.B. (2005). Relationships among psychosocial functioning, diagnostic comorbidity, and the recurrence of generalized anxiety disorder, panic disorder, and major depression. Journal of Anxiety Disorders, 19, 752-766. doi: 10.1016/j.janxdis.2 004.10 .002

Rosewater, L.B. (1988). Battered or schizophrenic? Psychological tests can't tell. In: K. Yllö \& M. Bograd (Eds.), Feminist perspectives on wife abuse (pp. 200-215). Thousand Oaks, CA: Sage.

Saunders, D.G. (1992). A typology of men who batter: three types derived from cluster analysis. American Journal of Orthopsychiatry, 62, 264-275. doi:10.1037/h0079333

Singh, V., Tolman, R., Walton, M., Chermack, S., \& Cunningham, R. (2014). Characteristics of men who perpetrate intimate partner violence. Journal of the American Board of Family Medicine, 27(5), 661-668. doi:10.3122/jabfm.2014. 05.130247

Stein, A. (2012). Engendered self-states: dissociated affect, social discourse, and the forfeiture of agency in battered women. Psychoanalytic Psychology, 29(1), 34-58. doi:10. $1037 / \mathrm{a} 0024880$

Stover, C.S., Meadows, A.L., \& Kaufman, J. (2009). Interventions for intimate partner violence: review and implications for evidence-based practice. Professional Psychology: Research and Practice, 40(3), 223-233. doi:10.1037/a0012718

Straus, M.A. (2011). Gender symmetry and mutuality in perpetration of clinical-level partner violence: empirical evidence and implications for prevention and treatment. Aggression and Violent Behavior, 16(4), 279-288. doi:10.1016/j.avb. 2011.04.010

Sullivan, C.M., \& Bybee, D.I. (1999). Reducing violence using community-based advocacy for women with abusive partners. Journal of Consulting and Clinical Psychology, 67(1), 43-53. doi:10.1037/0022-006X.67.1.43

Sullivan, C.M., Bybee, D.I., \& Allen, N.E. (2002). Findings from a community-based program for battered women and their children. Journal of Interpersonal Violence, 17, 915936. doi: 10.1177/0886260502017009001

Thompson, R.S., Bonomi, A.E., Anderson, M., Reid, R.J., Dimer, J.A., Carrell, D., \& Rivara, F.P. (2006). Intimate partner violence: prevalence, types, and chronicity in adult women. American Journal Of Preventive Medicine, 30(6), 447-457. doi:10.1016/j.amepre.2006.01.016

U.S. Attorney General (1994). Task Force on family violence: final report. Washington, DC: U.S. Department of Justice.

World Health Organization (2013). Responding to intimate partner violence and sexual violence against women: WHO clinical and policy guidelines. Geneva: World Health Organization.

Widom C.S., Czaja S.J., \& Dutton M.A. (2008). Childhood victimization and lifetime revictimization. Child Abuse Neglect, 32(8), 785-796. doi:10.1016/j.chiabu.2007.12.006

Zlotnick, C., Capezza, N.M., \& Parker, D. (2011). An interpersonally based intervention for low-income pregnant women with intimate partner violence: a pilot study. Archives of Women's Mental Health, 14(1), 55-65. doi:10.1007/s00737010-0195-X 